\title{
Predictors of success after bilateral epididymovasostomy performed during vasectomy reversal: A multi-institutional analysis
}

\author{
Jesse Ory, MD',2; Sirpi Nackeeran, $M D^{1}$; Udi Blankstein, $M D^{2}$; Joshua T. White, $M D^{2}$; Ethan Grober, $M D^{3}$; \\ Sheldon H. Marks, MD'; Ranjith Ramasamy, MD'
}

'Department of Urology, University of Miami, Miami, FL, United States; ${ }^{2}$ Department of Urology, Dalhousie University, Halifax, NS, Canada; 3 Department of Surgery, Division of Urology, University of Toronto, Toronto, ON, Canada; ${ }^{2}$ Department of Urology, University of Arizona College of Medicine, Tuscon, AZ, United States

Cite as: Ory J, Nackeeran S, Blankstein U, et al. Predictors of success after bilateral epididymovasostomy performed during vasectomy reversal: A multi-institutional analysis. Can Urol Assoc J 2022;16(3):E132-6. http://dx.doi.org/10.5489/cuaj.7441

Published online October 18, 2021

\section{Abstract}

Introduction: Vasectomy reversal (VR) represents an excellent option for paternity in men who desire to expand their family following vasectomy. Traditional VR via vasovasostomy has a success rate upwards of $90 \%{ }^{1,2}$ but when sperm or sperm parts are not present in vasal fluid, epididymovasostomy (EV) must be performed instead. Our objective was to determine which factors influence success after bilateral EV.

Methods: A prospectively maintained database with data from the U.S. and Canada was used to identify men who underwent bilateral EV at time of VR. Success was defined as motile sperm in any postoperative semen analyses. Multivariable logistic regression was used to identify predictors of success.

Results: A total of 200 men had at least one postoperative semen analysis, and 171 men were included in the analysis. Average age was 44.7 years, with average followup of seven months. Median time elapsed between vasectomy and EV was 15 years (interquartile range [IQR] 10-18). Overall success rate was 50\%. Despite the study being adequately powered, factors such as years since vasectomy (odds ratio [OR] 1.01, confidence interval [CI] 0.95-1.06), age (OR 0.96, Cl 0.91-1.01), intraoperative presence of motile sperm (OR 0.81, Cl 0.41-1.62), and epidydimal fluid characteristics did not predict success.

Conclusions: Bilateral EV at time of VR is successful in 50\% of cases in a multi-institutional, North American cohort. Microsurgeons can be reassured that neither time elapsed nor epididymal fluid characteristics negatively impact success rates as long as sperm or sperm parts are present. Surgeons performing VR should be comfortable and prepared to perform EV if indicated.

\section{Introduction}

Vasectomy is an effective and safe form of male contraception currently used by 42-60 million men worldwide. ${ }^{3}$ In 2015, over 500000 vasectomies were performed in the U.S. ${ }^{4}$ Of men who undergo vasectomy, approximately $6 \%$ of them will eventually seek a surgical reversal. ${ }^{5}$ Most men in this situation will undergo a vasovasostomy (VV); however, a smaller subset will require epididymovasostomy (EV). Men need an EV when there is epididymal obstruction, as evidenced by absence of sperm or sperm parts in the vasal fluid in conjunction with thick, pasty vasal fluid, ${ }^{6}$ and is more likely to be required if there is a prolonged obstructive interval. ${ }^{7,8}$

While multiple nomograms and prediction tools have been developed to predict the success of $\mathrm{VV},{ }^{9-11}$ and some of these studies include men who underwent EV, ${ }^{12}$ no models have looked specifically at men undergoing bilateral EV at time of vasectomy reversal (VR).

The success of an EV is highly dependent on specialized training in microsurgery. ${ }^{8,13}$ Recognizing that published patency rates and pregnancy rates after EV are lower than $\mathrm{V},{ }^{12}$ every factor that may influence success is imperative for the surgeon and patient to understand. Our objective was to use multi-institutional data to predict which factors influence success after bilateral EV at time of VR. We hypothesized that there may be preoperative and operative factors that predict a successful outcome.

\section{Methods}

Data from two high-volume institutions were collected from men undergoing VR. De-identified data were collected from a prospectively maintained database at both centers. Men were included if they underwent bilateral EV, or unilateral EV in the presence of a solitary testis, and if they had at least one 
postoperative semen analysis (SA). All VR were performed for fertility restoration. Men were excluded if the surgery was a re-do operation after a previously failed VR. Data collected from both centers included patient age, partner age, year of vasectomy and year of VR, postoperative SA, and intraoperative presence of sperm or sperm parts in the epididymal fluid. Additional data that was collected in the Arizona database included presence of sperm granuloma and additional intraoperative findings, including epididymal fluid volume, color, and consistency at creation of epididymal window. Epidydimal fluid characteristics were grouped by: large vs. small volume of epididymal fluid, watery vs. thick consistency of fluid, and white or clear in color vs. yellow or opaque. These were subjectively evaluated characteristics, assessed by the surgeon at the time of EV.

At both centers, EV was performed microscopically by high-volume infertility specialists. Residents, or other trainees when present, acted in an assistant role only. An end-toside intussusception technique was used, in which two 10-0 nylon sutures are used to pull an epididymal tubule into the lumen of the vas. ${ }^{14}$ In both centers, EV was performed if no sperm or sperm parts were found on vasal aspiration from the testicular end, and in the absence of clear vasal fluid.

SAs were checked as early as four weeks postoperatively. In cases where multiple SAs were present, the one with the highest total motile sperm count (TMSC) was used. Only one semen analysis at three months was available for each patient from the Toronto database, and so total followup and time to success was calculated using the Arizona data only.

The primary outcome was anastomotic success, which was defined as the presence of any motile sperm in the ejaculate postoperatively. This definition has been used previously ${ }^{15}$ and was chosen because it represents a straightforward definition for success that works well when comparing data between countries.

\section{Statistical analysis}

Statistical analyses were performed using SAS Studio, version 3.8. All men with data recorded for age, years since vasectomy, intraoperative sperm characteristics, epididymal fluid characteristics, and postoperative SA were included for analysis. Statistical significance of observed differences between continuous variables was assessed by t-test and observed differences in frequencies of values for categorical variables were assessed by Chi-squared test. We performed a series of simple logistic regression analyses to determine whether each variable of interest is associated with anastomotic success. We then included all variables in a multivariable logistic regression model after assessing for collinearity. As additional parameters were available from the Arizona data (epididymal fluid characteristics), these were analyzed separately in an additional multivariate regression model. A p-value $<0.05$ was considered statistically significant.

We calculated the appropriate sample size using previously accepted rules for sample size determination in multiple logistic regression, which suggest seeking a minimum sample of 20 observations per independent variable in the model if possible. ${ }^{16}$ We considered eight predicting variables in this model and, therefore, aimed to include a minimum of 160 patients for this study.

\section{Results}

We reviewed data from 226 men, of which 200 had at least one postoperative SA. Among these men, 100 (50\%) achieved anastomotic success. Of the 200 men with a postoperative SA, 171 men had complete data and were included for multivariable logistic regression analysis. Simple logistic regression was performed with the data available among all 200 men. Twenty-six men from Toronto and 174 men from Arizona were included. Average followup was seven months.

Average time to success (time from operation to first SA showing motile sperm) was 3.54 months (interquartile range [IQR] 1.99-3.97). In men who achieved patency, mean total motile sperm count was 33.88 million (IQR 6.49-42.84). The average age at time of reversal was 45.8 years (IQR 40-51), with an average time since vasectomy of 14.9 years (IQR 10-19). Ninety percent of men underwent bilateral VE, with the remaining undergoing unilateral EV. All baseline characteristics are outlined in Table 1.

Epididymal fluid characteristics (volume, color, consistency) were only tracked within Arizona data, while intraop-

\begin{tabular}{|c|c|c|}
\hline Possible predictors & Mean or frequency & $\mathbf{n}$ \\
\hline Age (years) & $45.8 \pm 8.0$ & 198 \\
\hline Years since vasectomy & $14.9 \pm 7.1$ & 197 \\
\hline Epididymal fluid volume & & 179 \\
\hline Large & $146(81.8 \%)$ & \\
\hline Small & $33(18.4 \%)$ & \\
\hline Epididymal fluid color & & 179 \\
\hline White/clear & $121(67.6 \%)$ & \\
\hline Yellow/murky & $58(32.4 \%)$ & \\
\hline Epididymal fluid consistency & & 179 \\
\hline Watery & $168(93.9 \%)$ & \\
\hline Creamy & $11(6.1 \%)$ & \\
\hline EV type & & 200 \\
\hline Bilateral & $180(90.0 \%)$ & \\
\hline Unilateral & $20(10.0 \%)$ & \\
\hline Intraoperative sperm characteristics & & 191 \\
\hline Motile & $147(77.0 \%)$ & \\
\hline Non-motile, fragmented, or absent & $44(23.0 \%)$ & \\
\hline
\end{tabular}


erative sperm data was recorded in both centers. Most men were found to have a large amount of epididymal fluid volume $(81.8 \%)$, white or clear epididymal fluid color $(67.6 \%)$, watery epididymal fluid consistency $(93.9 \%)$, and intact motile sperm visualized intraoperatively $(77.0 \%)$ (Table 1$)$. All patients had sperm or sperm parts seen in at least one tubule before EV was done. The mean age of the patients who achieved anastomotic success was three years younger than those who did not ( $p=0.0255)$; all other observed differences between mean values and frequencies of predictor variables were not statistically significant (Table 2).

In a series of simple logistic regression analyses, younger age was the only predictor associated with anastomotic success (odds ratio [OR] 0.96, 95\% confidence interval [CI] $0.93-1.00, p=0.0274)$. None of the other factors predicted success, including years since vasectomy $(0.97,0.93-1.01$, $\mathrm{p}=0.1410)$, large epididymal fluid volume $(1.53,0.70-3.33$, $\mathrm{p}=0.2887$ ), white or clear epididymal fluid color $(0.90$, $0.48-1.68, \mathrm{p}=0.7287)$, watery epididymal fluid consistency $(0.28,0.07-1.07, p=0.0629)$, unilateral EV $(0.39,0.14-1.07$, $\mathrm{p}=0.0666$ ), or presence of intraoperative motile sperm in the epididymal fluid $(0.88,0.45-1.72, p=0.7017)$ (Table 3$)$. When all variables were included in a multiple logistic regression model to identify independent predictors of success, none of the predictors were associated with success (Table 4). No epididymal fluid characteristics were identified as indepen-

\begin{tabular}{|c|c|c|c|}
\hline Possible predictors & Success & Failure & $\mathbf{p}$ \\
\hline Age (years) & $44.5 \pm 8.1$ & $47.1 \pm 7.9$ & 0.0255 \\
\hline Years since vasectomy & $14.2 \pm 7.1$ & $15.7 \pm 7.2$ & 0.1398 \\
\hline Epididymal fluid volume & & & 0.2866 \\
\hline Large & $68(46.6 \%)$ & $78(53.4 \%)$ & \\
\hline Small & $21(63.6 \%)$ & $12(36.4 \%)$ & \\
\hline Epididymal fluid color & & & 0.7291 \\
\hline White/clear & $53(43.8 \%)$ & $68(56.2 \%)$ & \\
\hline Yellow/murky & $27(46.6 \%)$ & $31(53.5 \%)$ & \\
\hline $\begin{array}{l}\text { Epididymal fluid } \\
\text { consistency }\end{array}$ & & & 0.0623 \\
\hline Watery & $71(42.3 \%)$ & $97(57.7 \%)$ & \\
\hline Creamy & $8(72.7 \%)$ & $3(27.3 \%)$ & \\
\hline EV type & & & 0.0593 \\
\hline Bilateral & $94(52.2 \%)$ & $86(47.8 \%)$ & \\
\hline Unilateral & $6(30.0 \%)$ & $14(70.0 \%)$ & \\
\hline $\begin{array}{l}\text { Intraoperative sperm } \\
\text { characteristics }\end{array}$ & & & 0.7015 \\
\hline Motile & $75(51.0 \%)$ & $72(49.0 \%)$ & \\
\hline $\begin{array}{l}\text { Non-motile, } \\
\text { fragmented, or absent }\end{array}$ & $21(47.7 \%)$ & $23(52.3 \%)$ & \\
\hline \multicolumn{4}{|c|}{$\begin{array}{l}\text { Significant differences between mean values of continuous variables and frequencies } \\
\text { of categorical variables were assessed using two-sample } t \text {-test and Chi-squared test, } \\
\text { respectively, with significance assessed as } p<0.05 \text {. EV: epididymovasostomy; SA: semen } \\
\text { analysis. }\end{array}$} \\
\hline
\end{tabular}

dent predictors of success in an additional multiple logistic regression evaluating only Arizona data (Table 5).

\section{Discussion}

When EV is required at the time of VR, the ideal characteristics to predict success are currently unknown. We used multi-surgeon, multi-institutional data from high-volume VR centers in the U.S. and Canada to determine predictors of success in men who underwent EV at the time of VR. We investigated patient and operative factors, including age, time since vasectomy, presence of motile sperm, and epididymal fluid characteristics. Surprisingly, we found that none of these factors predicted success on multivariate logistic regression.

We found that the obstructive interval was not associated with success. During VV, the obstructive interval has been considered one of the most important factors influencing the ability to proceed with VV. ${ }^{17}$ More contemporary series have shown that this decrease in success is largely due to unrecognized epididymal obstruction at the time of $\mathrm{VR}$, and can be avoided by performing a EV instead of VV. ${ }^{8,13,18}$ One potential cause to explain the significance of obstructive interval is that a longer obstructive interval increases both perivasal scarring and epididymal blowout, with subsequent proximal obstruction. ${ }^{17}$ In the case of VE, epididymal blowout and obstruction is less important, as the surgeon would be performing the anastomosis proximal to the level of obstruction. In our study, all but one epididymal tubule had sperm or sperm parts seen on microscopy prior to anastomosis, and so that obstruction would have been bypassed, explaining the insignificance of this variable in our prediction model.

Subjectively evaluated fluid characteristics that are generally considered to be optimal for VV success (larger volume, watery, clear fluid ${ }^{12,17}$ ) had no impact on the success of EV in our study. Furthermore, presence of motile sperm in tubular

\begin{tabular}{|c|c|c|c|}
\hline Independent variable & $\begin{array}{l}\text { OR EV success } \\
\quad(95 \% \mathrm{Cl})\end{array}$ & $\mathbf{p}$ & $\mathbf{n}$ \\
\hline Age (years) & $0.96(0.93-1.00)$ & 0.0274 & 198 \\
\hline Years since vasectomy & $0.97(0.93-1.01)$ & 0.1410 & 197 \\
\hline $\begin{array}{l}\text { Epididymal fluid volume (large } \\
\text { vs. small) }\end{array}$ & $1.53(0.70-3.33)$ & 0.2887 & 179 \\
\hline $\begin{array}{l}\text { Epididymal fluid color (white/ } \\
\text { clear vs. yellow/murky) }\end{array}$ & $0.90(0.48-1.68)$ & 0.7287 & 179 \\
\hline $\begin{array}{l}\text { Epididymal fluid consistency } \\
\text { (watery vs. creamy) }\end{array}$ & $0.28(0.07-1.07)$ & 0.0629 & 179 \\
\hline Unilateral vs. bilateral EV & $0.39(0.14-1.07)$ & 0.0666 & 200 \\
\hline Intraoperative motile sperm seen & $0.88(0.45-1.72)$ & 0.7017 & 191 \\
\hline
\end{tabular}

Table 3. Series of simple logistic regression analyses 
Factors influence success after bilateral epididymovasostomy

\begin{tabular}{|c|c|c|}
\hline Independent variable & $\begin{array}{l}\text { OR EV success } \\
(95 \% \mathrm{Cl})\end{array}$ & $\mathbf{p}$ \\
\hline Age (years) & $0.96(0.91-1.02)$ & 0.1638 \\
\hline Years since vasectomy & $1.01(0.95-1.07)$ & 0.8607 \\
\hline Unilateral vs. bilateral VE & $0.47(0.17-1.32)$ & 0.1539 \\
\hline Intraoperative motile sperm seen & $1.23(0.60-2.51)$ & 0.5654 \\
\hline
\end{tabular}

fluid did not appear to influence patency. Considering that EV was almost always performed on a tubule that revealed, at the minimum, sperm parts, this may explain the lack of association. Since the absence of sperm during $\mathrm{VV}$ is associated with higher failure rates, ${ }^{12}$ this scenario was avoided during $\mathrm{EV}$ s, as a dilated tubule can be identified visually prior to puncture, which resulted in the near uniform presence of sperm from the aspirate. If $\mathrm{EV}$ is going to be attempted, we suggest that until other factors are identified to characterize the "ideal" tubule, an extensive evaluation of tubular fluid characteristics, including motile sperm, may not be necessary, and the identification of a tubule with sperm or sperm parts is all that's needed to optimize outcomes.

Finally, age was seen to be a significant predictor of success on simple regression analysis, with younger men having higher anastomotic success. It is unlikely that this finding has any clinical significance, especially considering the difference became insignificant upon accounting for other predictors on multivariate regression analysis. Additionally, a larger series found older age was not predictive of pregnancy rates after VR. ${ }^{11}$ While this series included far fewer EVs than ours, the principle of age affecting anastomotic success does not seem to have a significant effect on success after accounting for other variables.

The patency rate of our cohort (50\%) falls within the range of published patency rates for bilateral EV during VR of $40-60 \%$. The definition of patency is important to consider when counselling patients. We defined ours as the presence of motile sperm. Previously published rates that used presence of motile sperm as a success parameter during EV at time of VR include $52 \%$ from a series of $100^{15}$ and $44 \%$ from a series of $45 .{ }^{19}$ Our success rate may be on the lower end due to our shorter followup of seven months; data shows that after EV, men can regain patency up to one year after surgery..$^{15}$ Some series report higher success rates, but these largely come from studies that define success as presence of any sperm, and often include EV for idiopathic obstruction, for which patency rates are higher. ${ }^{20}$ In these cases, EV success rates for primary obstructive azoospermia is often higher due to a number of factors, including better vas length and the ability to achieve a tension-free anastomosis. ${ }^{21}$

\begin{tabular}{|c|c|c|}
\hline Independent variable & $\begin{array}{l}\text { OR EV success } \\
(95 \% \mathrm{Cl})\end{array}$ & $\mathbf{p}$ \\
\hline Years since vasectomy & $1.04(0.98-1.11)$ & 0.2344 \\
\hline $\begin{array}{l}\text { Epididymal fluid volume (large vs. } \\
\text { small) }\end{array}$ & $1.14(0.49-2.65)$ & 0.7664 \\
\hline $\begin{array}{l}\text { Epididymal fluid color (white/clear } \\
\text { vs. yellow/murky) }\end{array}$ & $0.98(0.50-1.92)$ & 0.9522 \\
\hline $\begin{array}{l}\text { Epididymal fluid consistency } \\
\text { (watery vs. creamy) }\end{array}$ & $0.25(0.06-1.09)$ & 0.0651 \\
\hline Unilateral vs. bilateral VE & $0.57(0.18-1.79)$ & 0.3332 \\
\hline Intraoperative motile sperm seen & $1.06(0.48-2.34)$ & 0.8870 \\
\hline
\end{tabular}

To our knowledge, this is the largest study to evaluate predictors of success for EV done at the time of VR. The use of a similar technique between surgeons, as well as the multi-institutional nature of the study, adds to its validity and generalizability. Additionally, our study is adequately powered to support our conclusions.

There are a number of limitations with this study that must be acknowledged. The site of anastomosis was not recorded, and some data support that anastomosing to the body or tail of the epididymis is associated with higher patency rates. ${ }^{20}$ Both surgeons performed EV using the same technique (intussusception), ${ }^{14}$ so these data are only generalizable to surgeons following this approach to EV. In addition, the data from Toronto only included a single postoperative semen analysis done at three months, which may not accurately represent the true success rate, as patency can occur in a delayed fashion in men undergoing EV. Finally, our databases did not have complete pregnancy data, which is of highest interest to patients.

\section{Conclusion}

We present multi-institutional data on bilateral EV at time of VR and evaluate patient and operative factors as predictors of success. None of the factors investigated, including obstructive interval, intraoperative epididymal fluid characteristics, presence of motile sperm, or patient age, predicted success in a series with $50 \%$ anastomotic success rate. Surgeon experience, coupled with finding an epididymal tubule with sperm or sperm parts, is likely of paramount importance when performing this delicate surgery.

Competing interests: Dr. Gober has been an advisor for Paladin; has received education and research support from Boston Scientific; and owns stock in Pfizer. The remaining authors do not report any competing personal or financial interests related to this work.

This paper has been peer-reviewed. 


\section{References}

1. Herrel $L A$, Goodman $M$, Goldstein $M$, et al. Outcomes of microsurgical vasovasostomy for vasectomy reversal: A meta-analysis and systematic review. Urology 2015;85:819-25. htrps://doi.org/10.1016/i. urology.2014.12.023

2. Crosnoe $L E$, Kim ED, Perkins AR, et al. Angled vas cutter for vasovasostomy: Technique and results. Fertil Steril 2014;101:636-9.e2. https://doi.org/10.1016/i.fertnstert.2013.11.014

3. Pile JM and Barone MA. Demographics of vasectomy - U.S. and international. Urol Clin North Am 2009;36:295-305. https://doi.org/10.1016/j.ucl.2009.05.006

4. Ostrowski KA, Holt SK, Haynes B, et al. Evaluation of vasectomy trends in the United States. Urology 2018;118:76-9. https://doi.org/10.1016/j.urology.2018.03.016

5. Potts JM, Pasqualotto FF, Nelson D, et al. Patient characteristics associated with vasectomy reversal. J Urol 1999;161:1835-9. https://doi.org/10.1016/S0022-5347(05)68819-2

6. Sigman $M$. The relationship between intravasal sperm quality and patency rates after vasovasostomy. J Urol 2004;171:307-9. https://doi.org/10.1097/01.ju.0000102322.90257.8b

7. Mui P, Perkins A, Burrows PJ, et al. The need for epididymovasostomy at vasectomy reversal plateaus in older vasectomies: A study of 1229 cases. Andrology 2014;2:25-9. https://doi.org/10.1111/j.20472927.2013.00143.x

8. Fenig DM, Kattan MW, Mills JN, et al. Nomogram to preoperatively predict the probability of requiring epididymovasostomy during vasectomy reversal. J Urol 2012;187:215-8. https://doi.org/10.1016/i. juro.2011.09.026

9. Bolduc S, Fischer MA, Deceuninck G, et al. Factors predicting overall success: A review of 747 microsurgical vasovasostomies. Can Urol Assoc J 2007;1:388-94. hrtps://doi.org/10.5489/cuaj.454

10. Nagler HM and Jung H. Factors predicting successful microsurgical vasectomy reversal. Urol Clin North Am 2009;36:383-90. https://doi.org/10.1016/i.ucl.2009.05.010

11. Nusbaum DJ, Marks SF, Marks MBF, et al. The effect of male age over 50 years on vasectomy reversal outcomes. Urology 2020;145:134-40. https://doi.org/10.1016/i.urology.2020.04.141

12. Hsiao W, Goldstein M, Rosoff JS, et al. Nomograms to predict patency after microsurgical vasectomy reversal. J Urol 2012;187:607-12. https://doi.org/10.1016/i.juro.2011.10.044
13. Chawla $A, O^{\prime}$ Brien J, Lisi $M$, et al. Should all urologists performing vasectomy reversals be able to perform vasoepididymostomies if required? J Urol 2004;172:1048-50. https://doi.org/10.1097/01. ju. $0000135118.43383 . b 1$

14. Kirby EW, Hockenberry M and Lipshultz LI. Vasectomy reversal: Decision-making and technical innovations. Transl Androl Urol 2017;6:75360-760. https://doi.org/10.21037/tau.2017.07.22

15. Matthews GJ, Schlegel PN, Goldstein M. Patency following microsurgical vasoepididymostomy and vasovasostomy: Temporal considerations. J Urol 1995;154:2070-3. https://doi.org/10.1016/S0022$5347(01) 66697-7$

16. Applied Logistic Regression, 3rd Edition I Wiley. Available at: https://www.wiley.com/en-us/ Applied+Logistic+Regression\%2C+3rd+Edition-p-9780470582473. Accessed March 30, 2021.

17. Belker AM, Thomas AJ, Fuchs EF, et al. Results of 1469 microsurgical vasectomy reversals by the Vasovasostomy Study Group. J Urol 1991;145:505-11. https://doi.org/10.1016/S0022$5347(17) 38381-7$

18. Grober ED, Karpman E and Fanipour M. Vasectomy reversal outcomes among patients with vasal obstructive intervals greater than 10 years. Urology 2014;83:320-3. https://doi.org/10.1016/i. urology.2013.09.016

19. Schiff J, Chan P, Li PS, et al. Outcome and late failures compared in 4 techniques of microsurgical vasoepididymostomy in 153 consecutive men. J Urol 2005;174:651-5;quiz 801. https://doi.org/10.1097/01. ju.0000165573.53109.92

20. Yoon YE, Lee HH, Park SY, et al. The role of vasoepididymostomy for treatment of obstructive azoospermia in the era of in vitro fertilization: A systematic review and meta-analysis. Asian J Androl 2019;21:67-73. https://doi.org/10.4103/aja.aja_59_18

21. Peng J, Yuan Y, Zhang Z, et al. Patency rates of microsurgical vasoepididymostomy for patients with idiopathic obstructive azoospermia: A prospective analysis of factors associated with patency-single-center experience. Urology 2012;79:119-22. https://doi.org/10.1016/j.urology.2011.09.034

Correspondence: Dr. Ranith Ramasamy, Department of Urology, University of Miami, Miami, FL, United States; ramasamy@miami.edu 